\title{
Corrigendum: Release probability of hippocampal glutamatergic terminals scales with the size of the active zone
}

\section{Noemi Holderith, Andrea Lorincz, Gergely Katona, Balázs Rózsa, Akos Kulik, Masahiko Watanabe \& Zoltan Nusser} Nat. Neurosci. 15, 988-997 (2012); published online 10 June 2012; corrected after print 23 November 2015

In the version of this article initially published, Figure $7 \mathrm{~h}$ presented data from rat 2 but the corresponding legend gave statistics for rat 1 . The legend originally read, "Density of gold particles labeling the Cav2.1 subunit within presynaptic active zones (mean \pm s.d. $=395.8 \pm 154.8$ gold $\mu$ m ${ }^{-2}$, $n=34$ in rat 1 ) and in the surrounding extrasynaptic axonal plasma membrane (mean \pm s.d. $=1.6 \pm 2.4$ gold $\mu \mathrm{m}^{-2}, n=32$ in rat 1 ) in comparison with the background labeling calculated on E-face plasma membranes (mean \pm s.d. $=0.6 \pm 2.3$ gold $\mu \mathrm{m}^{-2}, n=39 ; P_{\text {synaptic }}<0.01, P_{\text {extrasynaptic }}=0.73$ )." It has been changed to give the statistics for rat 2: "Density of gold particles labeling the Cav2.1 subunit within presynaptic active zones (mean \pm s.d. $=293.8 \pm 122$ gold $\mu \mathrm{m}^{-2}, n=49$ in rat 2$)$ and in the surrounding extrasynaptic axonal plasma membrane $\left(\right.$ mean $\pm \mathrm{s} . \mathrm{d} .=2.8 \pm 4.0$ gold $\mu \mathrm{m}^{-2}, n=49$

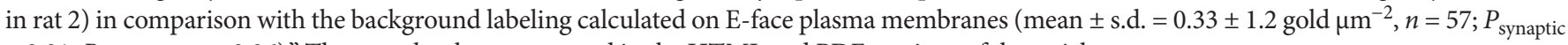
$\left.<0.01, P_{\text {extrasynaptic }}=0.06\right)$." The error has been corrected in the HTML and PDF versions of the article. 